\title{
Laboratory measurements of high-frequency, acoustic broadband backscattering from sea ice and crude oil
}

\author{
Christopher Bassett, ${ }^{\text {a) }}$ Andone C. Lavery, and Ted Maksym \\ Department of Applied Ocean Physics and Engineering, Woods Hole Oceanographic \\ Institution, Woods Hole, Massachusetts 02543 \\ cbassett@whoi.edu, alavery@whoi.edu,tmaksym@whoi.edu \\ Jeremy P. Wilkinson \\ British Antarctic Survey, Cambridge, United Kingdom \\ jpw28@bas.ac.uk
}

\begin{abstract}
Recent decreases in summer sea ice cover are spurring interest in hydrocarbon extraction and shipping in Arctic waters, increasing the risk of an oil spill in ice covered waters. With advances in unmanned vehicle operation, there is an interest in identifying techniques for remote, underwater detection of oil spills from below. High-frequency $(200-565 \mathrm{kHz})$, broadband acoustic scattering data demonstrate that oil can be detected and quantified under laboratory grown sea ice and may be of use in natural settings. A simple scattering model based on the reflection coefficients from the interfaces agrees well with the data.

(C) 2014 Acoustical Society of America

[GD]

Date Received: August 13, 2014 Date Accepted: November 3, 2014
\end{abstract}

\section{Introduction}

It is estimated that as much as $13 \%$ of the world's undiscovered oil is located in the Arctic, mostly in offshore waters less than $500 \mathrm{~m}$ deep. ${ }^{1}$ Because of technological advances, the retreat of Arctic sea ice extent, and other economic and political factors, further hydrocarbon extraction in Arctic waters is increasingly likely. With areas of significant new exploration offshore likely on the Alaskan outer continental shelf ${ }^{2}$ there is the potential for an oil spill in areas that are seasonally covered by drifting pack ice. Airborne techniques for detection of oil trapped beneath pack ice have not yet proven effective in complex ice conditions, and on-ice techniques are logistically difficult in such an environment. ${ }^{2}$ However, improvements in under ice operation of autonomous vehicles $s^{3}$ have opened up the possibility of oil spill detection from below a floating ice cover. To develop this capability, analysis of the efficacy of sensors for oil detection in a variety of ice conditions is required.

Congelation ice, also referred to as columnar ice, forms during calm sea conditions. Under turbulent conditions initial ice formation can take a different form (e.g., frazil ice). After the frazil layer consolidates additional thickening occurs in the form of congelation ice, which constitutes the majority of the Arctic ice pack. ${ }^{4}$ Congelation ice forms through the downward vertical growth of crystals into the ocean below. However, in the presence of saltwater, as is typical in freezing of binary mixtures, a pure solid is not formed, but rather a complex mixture of ice and liquid brine. As the ice continues to grow the brine layers begin to freeze as they continue to cool, pinching off into pockets of dense brine and a series of vertical channels that allow brine expelled during freezing to drain into the sea water. At the base of the columnar

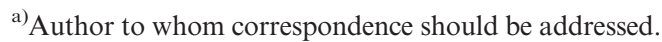


crystals near the water/ice interface there are narrow, planar dendrites interspersed with brine inclusions. The columnar crystals are typically less than a few centimeters in diameter while the spacing of the dendrites is $1 \mathrm{~mm}$ or less. The volume of brine within the bottom portion of the ice is determined by the amount of trapped salt and the ice temperature, which affect the connectivity of the brine. In this zone near the base of the ice, referred to as the skeletal layer, the bulk properties vary between those of sea water and pure ice.

This work focuses on the use of acoustic backscattering techniques for the detection and characterization of crude oil under a growing sheet of congelation ice. The physical scales associated with the complex structure of the skeletal layer suggest that high-frequency $(>10 \mathrm{kHz})$ acoustic scattering techniques are well suited to studies aimed at remotely characterizing sea ice. ${ }^{5-9}$ The results presented here demonstrate that high-frequency, broadband techniques can be applied in both the temporal and frequency domains to identify a thin layer of crude oil, approximately $4 \mathrm{~cm}$ thick, beneath laboratory-grown congelation ice. Additionally, the measurements performed here suggest that the structure of the skeletal layer is significantly modified by the presence of even a very thin layer of oil, thinner than the oil layer thickness resolvable given the available bandwidth. The corresponding changes observed in the acoustic backscattering may provide another potential avenue of information for detecting and characterizing even very thin oil layers under congelation ice.

\section{Methods}

Measurements of high-frequency broadband acoustic scattering of sea ice and crude oil under sea ice were conducted in a $2000 \mathrm{~L}(1.37 \mathrm{~m}$ deep, $1.4 \mathrm{~m}$ in diameter) cylindrical tank in a cold room at Hamburgische Schiffbau-Versuchsanstalt GmbH (HSVA) in Hamburg, Germany from December 12-20, 2013. Throughout the experiment the room temperature was maintained at $-18^{\circ} \mathrm{C}$. A few hours before ice growth began on December 12, a uniform salinity profile $(>99.8 \% \mathrm{NaCl})$ of approximately $32 \mathrm{PSU}$ was measured in the tank using a RBR concerto conductivity, temperature, and depth (CTD) logger. The range to the surface prior to ice growth was $90 \mathrm{~cm}$. Ice growth proceeded uninterrupted until the afternoon of December 16, at which point the acoustically inferred range to the water/ice interface was $78 \mathrm{~cm}$, suggesting an ice thickness of $12 \mathrm{~cm}$ [Fig. 1(a)]. At that point $50 \mathrm{~L}$ of North Sea medium crude oil (API gravity $=30.75$ ) was deployed through a pipe frozen into the ice using hydrostatic pressure; care was taken to avoid introducing air.

The pulse-echo system (Ref. 10, Fig. 2) was controlled by a National Instruments (NI) data acquisition system (PXI-1000B) with an embedded computer controller (PXI-8175, Windows 2000) and a custom LabView script. Transmitted signals were generated by a 12-bit, $40 \mathrm{MHz}$ Arbitrary Waveform Generator (PXI-5411) and amplified (ENI 2100L: $50 \mathrm{~dB}$ gain). A signal sampler (Ritec SS-40, $-40 \mathrm{~dB}$ ) immediately following the amplifier was used to record the transmitted signal. Received signals were filtered and preamplified (RITEC Inc., Model BR-640 A). The transmitted and received signals were sampled at $4 \mathrm{MHz}$.

The acoustic backscatter measurements were obtained using multiple pairs of identical transducers mounted near the bottom of the tank. After the oil deployment, the range to the water/oil interface was $74 \mathrm{~cm}$ [Fig. 1(b)]. The transducers in each pair were closely spaced $(<1 \mathrm{~cm}$ separation distance between transducers) to approximate monostatic measurements. The transducer pairs included $250 \mathrm{kHz}$ and $500 \mathrm{kHz}$ center frequency piston-like transducers (see Ref. 10, Table I, for details). The transmitted signals were $250 \mu$ s linearly modulated chirps from $200-300 \mathrm{kHz}$ and $350-565 \mathrm{kHz}$.

The backscatter data analyzed here were obtained every morning throughout the experiment with the exception of the weekend. When time permitted additional data were obtained in the afternoons. A third data set was also obtained on December 16 immediately following the release of the oil. During sampling periods each transducer pair pinged a minimum of 30 times at $1 \mathrm{~Hz}$. The observed backscattering from the interfaces did not vary over such short time periods so the pings were ensemble 

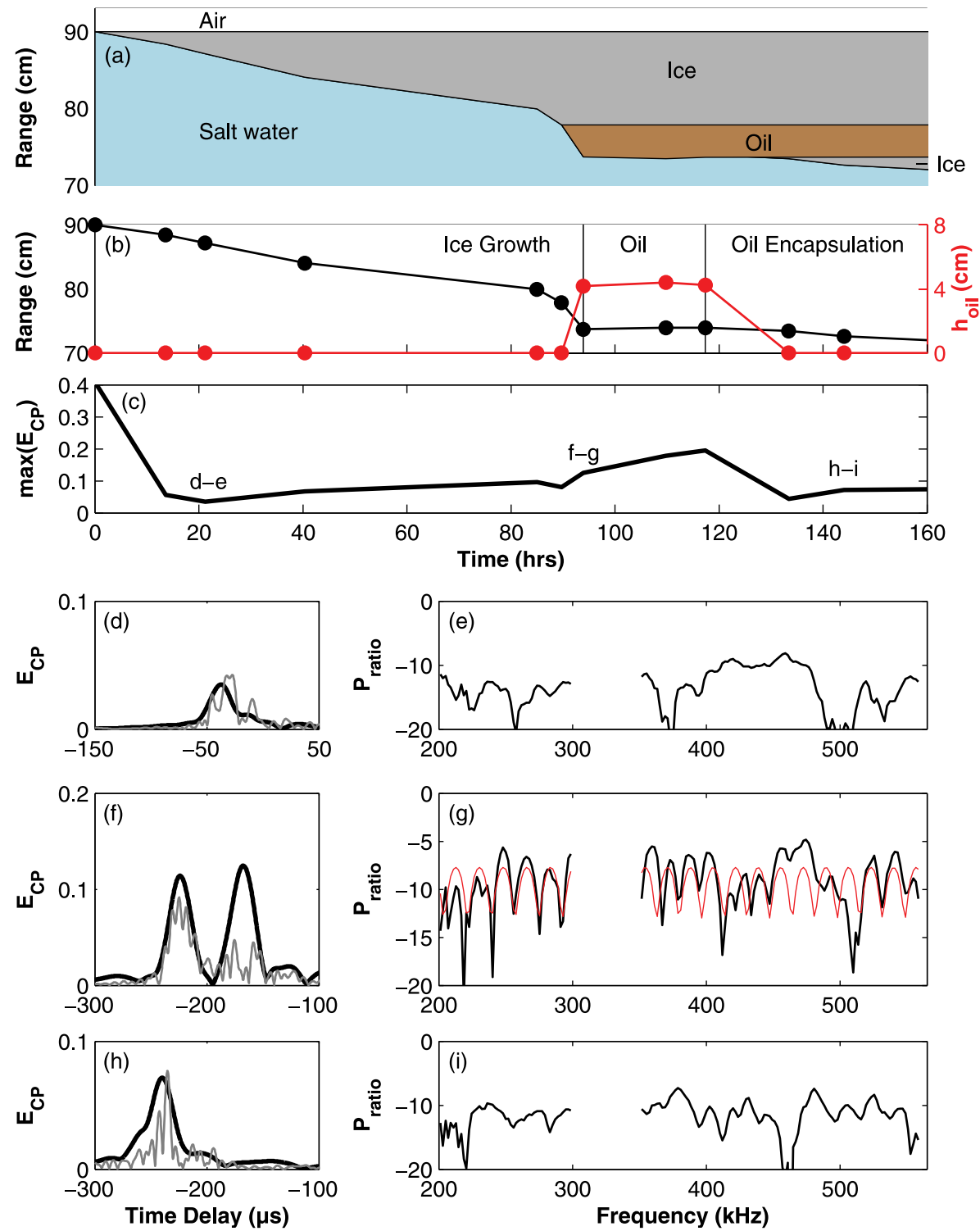

Fig. 1. (Color online) (a) Time series, linearly interpolated from the data in (b), showing the stages of the experiment. (b) Time series of inferred range to the bottom interface (ice or oil) based on the change in time delay from the pressure release surface and the acoustically inferred oil thickness. (c) Time series of the maximum value of $E_{\mathrm{CP}} . E_{\mathrm{CP}}$ (black $200-300 \mathrm{kHz}$; gray $350-565 \mathrm{kHz}$ ) and $P_{\text {ratio }}$ during each of the stages of the experiment-ice growth [(d)-(e)], oil under ice [(f)-(g)], and oil encapsulation [(h)-(i)]. The model is compared to $P_{\text {ratio }}$ (black) in (g).

averaged. The data in Fig. 1(b) show the elapsed time, from the beginning of the experiment, at which the data were obtained.

The water/air pressure release surface was used to calibrate the system. Prior to ice growth, the tank was covered and allowed to settle overnight to minimize the surface disturbances. The transmitted and surface-reflected signals were recorded and processed for calibration. Assuming the surface is acoustically smooth, the received calibration voltage signals, $v_{\mathrm{cal}}^{R}(t)$, are phase-shifted replicas of the transmitted signals.

Backscattering measurements were analyzed using pulse compression techniques, which increase signal-to-noise ratios and temporal resolution. ${ }^{11}$ The compressed 
pulse (CP) output is obtained by cross-correlating the received voltage time series with the received calibration time series

$$
\mathrm{CP}(t)=k_{\mathrm{CP}}^{-1} v^{R}(t) \otimes v_{\mathrm{cal}}^{R}(t),
$$

where $v^{R}(t)$ is the received voltage time series, $\otimes$ is the cross-correlation, and $k_{\mathrm{CP}}$ is the autocorrelation function of the received calibration time series at zero time lag. The temporal data are presented in terms of the envelope of the CP output, $E_{\mathrm{CP}}$.

By assuming that the largest peak in the $\mathrm{CP}$ output is associated with the mean range to the bottom interface, the range is given by the following: $r=\left(c_{\mathrm{w}} / 2\right) t$, where $c_{\mathrm{W}}$ is the sound speed of the water $\left(c_{\mathrm{W}}=1440 \mathrm{~m} / \mathrm{s}\right)$ and $t$ is the delay time to the first interface peak in $E_{\mathrm{CP}}$. Once introduced, the buoyant oil forms a layer under the ice and the pulse compression output contains peaks from both interfaces. The thickness of the oil is then given by the following: $h_{\mathrm{oil}}=\left(c_{\mathrm{oil}} / 2\right)\left(t_{\mathrm{oil}, \text { ice }}-t_{\mathrm{w}, \mathrm{oil}}\right)$, where $c_{\mathrm{oil}}$ is the sound speed of the oil, and $t_{\text {oil,ice }}$ and $t_{\mathrm{w}, \text { oil }}$ are the time delays that correspond to the peaks in $E_{\mathrm{CP}}$ associated with the oil/ice and water/oil interfaces, respectively.

The frequency-dependent scattering is presented in the form

$$
P_{\text {ratio }}(\omega)=\frac{P_{\text {scat }}(\omega)}{P_{\text {inc }}(\omega)}=G(\omega) \frac{V^{R}(\omega)}{V_{\text {cal }}^{R}(\omega)} \frac{r_{\text {scat }}}{r_{\text {cal }}},
$$

where $\omega$ is the angular frequency, $P_{\text {scat }}$ is the amplitude of the scattered pressure, $P_{\text {inc }}$ is the amplitude of the incident pressure at the scattering interface, $r_{\text {scat }}$ is the range to the scattering interface, and $r_{\mathrm{cal}}$ is the range to the pressure release surface during calibration. $V^{R}(\omega)$ and $V_{\text {cal }}^{R}(\omega)$ are the absolute values of the Fourier transforms of the received voltage time series and the received calibration voltage time series, respectively. $G(\omega)=V_{\text {cal }}^{T}(\omega) / V^{T}(\omega)$ is the ratio of the absolute value of the Fourier transform of the transmitted calibration voltage time series to the absolute value of the transmitted voltage time series. This formulation of the scattering data, used previously in studies of scattering from cylinders ${ }^{12}$ and double-diffusive microstructure, ${ }^{13}$ accounts for the range dependence of the incident pressure, but not the range dependence of the scattered pressure. Therefore, directly comparing the results at different ranges may be inappropriate. If the scattering is assumed to be consistent with that from a smooth interface, then $P_{\text {ratio }}$ reduces to the reflection coefficient. Attenuation in the water is neglected in this analysis due to the short ranges $\left(r_{\text {scat }}<1 \mathrm{~m}\right)$.

\section{Results}

The acoustically inferred range to the bottom interface throughout the experiment are included in Figs. 1(a) and 1(b). The maximum of $E_{\mathrm{CP}}$, which is an approximation of the reflection coefficient, is plotted in Fig. 1(c). When the ice is thin, the reflection coefficient is high $(>0.3)$ but decreases rapidly with ice growth. $E_{\mathrm{CP}}$ then remains less than 0.1 until the oil is introduced. The introduction of the oil increases $E_{\mathrm{CP}}$ until encapsulation occurs and $E_{\mathrm{CP}}$ decreases again. After the oil was introduced the acoustically inferred range to the water/oil interface remained constant until oil encapsulation began and ice growth continued. The acoustically inferred oil thickness from $E_{\mathrm{CP}}$ $(200-300 \mathrm{kHz})$ was $4.2 \mathrm{~cm}$ prior to encapsulation. Following the encapsulation of the oil, the received signals no longer contained clear peaks from multiple interfaces.

Examples of the high-frequency, broadband scattering from growing sea ice and crude oil under sea ice are included in Figs. 1(d)-1(i) in both the temporal (lefthand column) and frequency (right-hand column) domains. As shown in pre- and postoil measurements, the scattered signals using the $200-300 \mathrm{kHz}$ transducers are easier to interpret than the higher frequency transducers because there is a single peak associated with each interface. The envelopes from the $350-565 \mathrm{kHz}$ transducers are more difficult to interpret due to the presence of additional peaks that are not resolved in the $200-300 \mathrm{kHz}$ data [Figs. 1(d), 1(f), and 1(h)]. This complexity is attributed to a combination of the increased temporal resolution and roughness of the basal structure relative to the acoustic wavelength. 


\section{Comparison of results to a simple 1-D weak-scattering model for the oil layer}

To model the frequency spectra following the introduction of the oil, the water/oil and oil/ice interfaces are assumed to be smooth and infinite. Weak scattering is assumed so only the first reflection is considered. Previous work has shown high-frequency attenuation in the ice to be significant ${ }^{5}$ so reflections from the ice/air interface are neglected. Attenuation in the oil is also neglected. These assumptions result in a frequencydependent total reflection coefficient with interference patterns related to the sound speed, oil thickness, and reflection coefficients at the interfaces. This term is described by

$$
\mathcal{R}_{\text {model }}(k)=\frac{\mathcal{R}_{\mathrm{w}, \text { oil }}+\mathcal{R}_{\text {oil }, \text { ice }} \mathrm{e}^{2 \mathrm{j} k h_{\text {oil }}}}{1+\mathcal{R}_{\mathrm{w}, \text { oil }} \mathcal{R}_{\text {oil }, \text { ice }} \mathrm{e}^{2 \mathrm{j} k h_{\text {oil }}}},
$$

where $\mathcal{R}$ is a reflection coefficient calculated for each interface, $k$ is the vertical wave number in the oil, $h_{\text {oil }}$ is the thickness of the crude oil layer, and the subscript w refers to the water. The reflection coefficients are related to the mismatch in the acoustic impedance at each interface. The water properties $\left(c_{\mathrm{w}}=1440 \mathrm{~m} / \mathrm{s}, \rho_{\mathrm{w}}=1025 \mathrm{~kg} / \mathrm{m}^{3}\right)$ are based on the CTD measurements. The skeletal layer and bulk properties of the ice vary based on their structure and brine content, so sea ice can be modeled acoustically using sound speed profiles dependent on the range from the water/ice interface. ${ }^{7-9,14}$ Because of the high frequencies used in this work, reflection from the sea ice is modeled based on the impedance mismatch at the interface where the ice properties are $c_{\text {ice }}=1700 \mathrm{~m} / \mathrm{s}$ and $\rho_{\text {ice }}=960 \mathrm{~kg} / \mathrm{m}^{3}$, which are similar to values previously used to model reflections from ice. ${ }^{7-9,14}$ The properties of oil, $c_{\text {oil }}=1475 \mathrm{~m} / \mathrm{s}$ and $\rho_{\text {oil }}=885 \mathrm{~kg} /$ $\mathrm{m}^{3}$, are based on empirical formulations for the properties of crude oil using the API gravity at $0^{\circ} .{ }^{15}$ At the time of deployment the crude oil was approximately $5^{\circ} \mathrm{C}$; no temperature measurements of the oil are available post-deployment. Given these sound speeds and densities, the reflection coefficients are $\mathcal{R}_{\mathrm{w}, \text { oil }}=0.06$ and $\mathcal{R}_{\text {oil, ice }}=0.11$. The density value used for the ice represents a mixture of brine and ice and is difficult to measure in practice. However, the sound speed contrast at the oil/ice interface is much greater than the density contrast so the model is relatively insensitive to a realistic range of densities. In the absence of oil, the reflection coefficient from the water/ice interface is $\mathcal{R}_{\mathrm{w} \text {,ice }}=0.05$, which is consistent with previously reported values for sea ice at high-frequencies ${ }^{5-8,14}$ and the data in Fig. 1(c) prior to the introduction of oil.

The spectra and model comparisons included in Fig. 1(f) show that the model captures the peaks and nulls of the spectra with better performance at lower frequencies due to the previously described temporal resolution and relative roughness of the interfaces. The acoustically inferred oil thickness, $h_{\mathrm{oil}}$, from the $200-300 \mathrm{kHz} E_{\mathrm{CP}}$ is $4.2 \mathrm{~cm}$. $\mathcal{R}_{\text {model }}$ for the $200-300 \mathrm{kHz}$ and $350-565 \mathrm{kHz}$ data were determined by minimizing the rms error of the model with different oil thicknesses bounded by the $h_{\text {oil }}$ obtained in the temporal domain. The modeled data in Fig. 1(g) used oil thickness of $4.2 \mathrm{~cm}(200-300 \mathrm{kHz})$ and $4.4 \mathrm{~cm}(350-565 \mathrm{kHz})$. Figures $1(\mathrm{~h})$ and $1(\mathrm{i})$ show the $E_{\mathrm{CP}}$ and $P_{\text {ratio }}$ following oil encapsulation, which do not clearly indicate the presence of an oil layer. Post-experiment ice cores showed that the encapsulation of oil produced a distinct, contiguous layer of oil separating the two crystallographically unconnected layers of ice with only small amounts of percolation into the brine channels near the oil/ice interface. This is consistent with previous studies that showed that, with the exception of melting periods when brine channels open, enabling vertical migration, oil entrainment is limited to low concentrations $(<5 \%$ by vol.) within the relatively highporosity skeletal layer and discrete brine channels near the oil/ice interface. ${ }^{16,17}$

\section{Discussion}

The results presented in Sec. 4 demonstrate that high-frequency, broadband acoustic scattering techniques can be used to identify crude oil spills under congelation ice in a controlled, laboratory environment. Detection of crude oil spills using active acoustics requires balancing two competing considerations regarding the range resolution of 
transducers: (1) resolution must be sufficient to resolve both the water/oil and oil/ice interfaces and (2) increases in frequency and range resolution complicate the interpretation of scattered signals due to the roughness of the interfaces. Reported equilibrium thicknesses of crude oil under "smooth" ice range from $0.5-1 \mathrm{~cm}$ to $2 \mathrm{~cm}$ or more. ${ }^{18-20}$ However, in a natural environment, oil is expected to spread in a thin lens following underwater topography with deeper pools in under-ice depressions. This would result in oil being present under only a fraction of the ice but with thickness varying from those expected under smooth ice to tens of centimeters or more. ${ }^{21}$

The application of high-frequency, broadband techniques to oil spill detection requires further studies to inform interpretation of the scattered signals. In this experiment, the data were easiest to interpret at the lowest frequencies, $200-300 \mathrm{kHz}$, with a corresponding range resolution of roughly $1 \mathrm{~cm}$. In future work, spanning a lower frequency range (e.g., $80-500 \mathrm{kHz}$ ) could provide a balance between signal complexity and resolution across the range of potential oil thicknesses. The roughness and correlation lengths of both sea ice and crude oil under sea ice will affect scattering and are needed for the further development of models. There is also a need to study the impact of the beamwidth and the corresponding acoustic footprint, which varies by frequency for broadband transducers. Proper quantification of scattering from sea ice and oil under ice would also benefit from studies of the range dependence of scattering from these interfaces. Previous studies indicate that for the frequencies discussed here there is a transition between different statistical distributions, ${ }^{5,6}$ suggesting roughnesses between the asymptotic scattering regimes of smooth interfaces and point scatterers. Finally, future studies should consider the impact of oil on the structure of the skeletal layer and the implications for acoustic scattering.

\section{Acknowledgments}

The authors would like to thank the staff at HSVA, especially Karl Ulrich-Evers, for their organizational, logistical, and technical support. In addition, we thank Dale Chayes and Chris Callinan for their help during the experiment. Funding for the work was provided by the U.S. Bureau of Safety and Environmental Enforcement contract number E12PC00053. C.B. was supported by the WHOI Postdoctoral Scholar Program with funding provided by the United States Geological Survey.

\section{References and links}

${ }^{1}$ D. L. Gautier, K. J. Bird, R. R. Charpentier, A. Grantz, D. W. Houseknecht, T. R. Klett, T. E. Moore, J. K. Pitman, C. J. Schenk, J. H. Schuenemeyer, K. Sørensen, M. E. Tennyson, Z. C. Valin, and C. J.

Wandrey, "Assessment of undiscovered oil and gas in the Arctic," Science 324(5931), 1175-1179 (2009).

${ }^{2}$ National Research Council, Responding to Oil Spills in the U.S. Arctic Marine Environment (National Academies Press, Washington, DC, 2014).

${ }^{3}$ C. Kunz, C. Murphy, H. Singh, C. Willis, R. Sohn, S. Singh, T. Sato, C. Roman, K. Nakamura, M. Jakuba, R. Eustice, R. Camilli, and J. Bailey, "Toward extraplanetary under-ice exploration: Robotic steps in the Arctic," J. Field Robot. 26(4), 411-429 (2009).

${ }^{4}$ W. F. Weeks, On Sea Ice (University of Alaska, Fairbanks, Alaska, 2010), pp. 78-143.

${ }^{5}$ T. K. Stanton, K. C. Jezek, and A. J. Gow, "Acoustical reflection and scattering from the underside of laboratory grown sea ice: Measurements and predictions," J. Acoust. Soc. Am. 80(5), 1486-1494 (1986).

${ }^{6}$ K. C. Jezek, T. K. Stanton, A. J. Gow, and M. A. Lange, "Influence of environmental conditions on acoustical properties of sea ice," J. Acoust. Soc. Am. 88(4), 1903-1912 (1990).

${ }^{7}$ G. R. Garrison, R. E. Francois, and T. Wen, "Acoustic reflections form arctic ice at 15-300 kHz," J. Acoust. Soc. Am. 90(2), 973-984 (1991).

${ }^{8}$ K. L. Williams, G. R. Garrison, and P. D. Mourad, "Experiment examination of growing and newly submerged sea ice including acoustic probing of the skeletal layer," J. Acoust. Soc. Am. 92(4), 2075-2092 (1992).

${ }^{9}$ P. D. Mourad and K. L. Williams, "Near-normal incidence scattering from rough, finite surfaces: Kirchhoff theory and data comparison for arctic ice," J. Acoust. Soc. Am. 94(3), 1584-1597 (1993).

${ }^{10}$ C. Bassett, A. C. Lavery, and T. Maksym, "Laboratory measurements of high-frequency, broadband acoustic scattering of growing sea ice and oil beneath sea ice," Proc. Meet. Acoust. 21, 1-8 (2014).

${ }^{11} \mathrm{D}$. Chu and T. K. Stanton, "Application of pulse compression techniques to broadband acoustic scattering by live individual zooplankton,” J. Acoust. Soc. Am. 104(1), 39-55 (1998). 
${ }^{12}$ D. T. DiPerna and T. K. Stanton, "Fresnel zone effects in the scattering of sound by cylinders of various lengths," J. Acoust. Soc. Am. 90(6), 3348-3355 (1991).

${ }^{13}$ A. C. Lavery and T. Ross, “Acoustic scattering from double-diffusive microstructure," J. Acoust. Soc. Am. 122(3), 1449-1462 (2007).

${ }^{14}$ D. P. Winebrenner, "Acoustic backscattering from sea ice at high frequencies," Rep. APL-UWTR 9017, Technical report, Applied Physics Laboratory, University of Washington, Seattle, WA (1991).

${ }^{15}$ M. Batzle and Z. Wang, "Seismic properties of pore fluids," Geophysics 57(11), 1396-1408 (1992).

${ }^{16}$ NORCOR Engineering and Research Ltd., "The interaction of crude oil with Arctic sea ice," Beaufort Sea Technical Report No. 27 (Department of the Environment, Beaufort Sea Project, Victoria, British Columbia, Canada), $201 \mathrm{pp}$

${ }^{17} \mathrm{~J}$. Karlsson, C. Petrich, and H. Eicken, "Oil entrainment and migration in laboratory-grown saltwater ice," in Proceedings of the 21 st Conference on Port Ocean Engineering Under Arctic Conditions, Montreal, Canada (2011).

${ }^{18}$ B. E. Keevil and R. Ramseier, "Behavior of oil spilled under floating ice," in Proceedings of the 1975 Conference on Prevention and Control of Oil Pollution, Washington, DC (1975), pp. 497-501.

${ }^{19}$ G. D. Greene, P. J. Leinonen, and D. Mackay, "An exploratory study of the behaviour of crude oil spills under ice," Can. J. Chem. Eng. 55, 696-700 (1977).

${ }^{20}$ A. Kovacs, R. M. Morey, D. F. Cundy, and G. Decoff, "Pooling of oil under sea ice," in Proceedings of the International Conference on Port and Ocean Engineering Under Arctic Conditions, Quebec City, Quebec, Canada (1981).

${ }^{21}$ J. P. Wilkinson, P. Wadhams, and N. E. Hughes, "Modelling the spread of oil under fast sea ice using threedimensional multibeam sonar data," Geophys. Res. Lett. 34(L22506), 1-5, doi:10.1029/2007GL031754 (2007). 